\title{
Ritual y materialidad en Abidos: la estela CG 20570
}

Andrea P. Zingarelli*

\section{Resumen}

En este artículo se presentará la traducción y un estudio de la estela inédita CG 20570, actualmente depositada en el Museo Egipcio de El Cairo. Se realizará un análisis epigráfico e iconográfico con particular énfasis en la fórmula de ofrenda y las ofrendas exhibidas, comprendiendo sus aspectos rituales y materiales. La estela, que registra la existencia del visir Dedumontu Senebtyfy y su familia, formaba parte del paisaje de Abidos en el Reino Medio tardío. Fue hallada en el área de Kom el-Sultan, cercana al templo de Osiris y a la vía procesional donde transcurrían las celebraciones en honor al dios Osiris.

\section{Ritual and materiality at Abydos: the stela CG20570}

\begin{abstract}
This article will present the translation and study of the unpublished stela CG 20570, currently stored in the Egyptian Museum in Cairo. An epigraphic and iconographic analysis will be carried out, with particular emphasis on the offering formula and the involved offerings displayed. Their ritual and material aspects will be taken into account. The stela records the existence of the vizier Dedumontu Senebtyfy and his family and was part of the Abydos landscape in the Late Middle Kingdom. It was found in Kom el-Sultan area, close to Osiris Temple, and to the processional walkway where the celebration in honor of Osiris God took place.
\end{abstract}

Recibido: 29 de julio de 2019

Aceptado:

10 de diciembre de 2019

Palabras clave

Estela

Ofrendas

Abidos

Reino Medio Tardío

Keywords

Stela

Offerings

Abydos

Late Middle Kingdom

* Centro de Estudios de Sociedades Precapitalistas, Instituto de Investigaciones en Humanidades y Ciencias 


\section{Introducción}

La estela CG 20570 que alberga el Museo del Cairo es, junto con una estatua CG 427, la única evidencia de la existencia del visir Dedumontu Senebtyfy; y no sólo de este visir, sino de su hermano Nesmontu Seneb, un "superintendente de disputas" y de otros miembros de su familia (Figura 1). Dedumontu Senebtyfy y Nesmontu Seneb están sentados en un registro focal enfrentados delante de una mesa de ofrendas, compartiéndola y en un plano de igualdad. Esta parece ser una característica de las estelas del Reino Medio tardío donde se presentan personas en una mayor apariencia "igualitaria", a diferencia de las estelas del Reino Medio temprano, más enfocadas en el propietario sentado con su esposa y la familia y servidores en un plano secundario. El patrón en el Reino Medio tardío también parece ser el de enterramientos múltiples. Grajetzki (2007), lo vincula a las nuevas formas de representación de la gente en los monumentos. Los dos tienen nombres dobles y esta también era una práctica común en todos los niveles sociales en el Reino Medio tardío (Vernus, 1986). Asimismo, en esta estela particular se enfatizan las relaciones matrilaterales a partir de la madre del visir Dedumontu Senebtyfy y de Nesmontu Seneb, llamada Hebgeget/It, quien se halla sentada debajo de éstos, en el primer cuadrante derecho. Ella es el nexo entre nuestros dos protagonistas y el resto de sus hermanos, que observamos sentados en los cuadrantes izquierdos de la estela.

La estela fue encontrada en Abidos, en el área de Kom el-Sultan "la colina del sultán", en el ángulo noroeste del recinto, por Auguste Mariette (1880a). Según el propio Mariette (1880b, p. 225) fue elaborada "para servir de epitafio en una tumba común de dos personas". Además de esta breve sugerencia y de mencionar que su estilo no es cuidado, publica la transcripción de los nombres y los títulos de Dedumontu Senebtyfy y Nesmontu Seneb y de algunos de los que denomina "parientes", refiriéndose a los otros representados. En su publicación Catalogue Général des Monuments d’Abydos, Mariette la incluye en las estelas de la dinastía XII y la clasifica con el número 755.

Posteriormente, una transcripción completa sin traducción fue publicada por Lange y Schäfer (1908) con el número 20570 en Grab-und Denksteine des Mittleren Reichs im Museum von Kairo, No. 20400 - 20780, el volumen 2 del Catalogue général des antiquités égyptiennes du Musée du Caire. En este catálogo de las estelas del Museo del Cairo, es descripta como una representación de forma simple, con las figuras de siluetas y jeroglíficos rellenos de negro. No se traducen los textos, simplemente se ofrecen una valiosa transcripción y una descripción de la estela.

Lamentablemente, poco sabemos del contexto arqueológico. Cientos de estelas fueron recogidas en las excavaciones arqueológicas de fines del siglo XIX y principios del XX y derivadas a distintos museos. Antes de ello, entre 1820 y 1850 Giovani d'Athanasi y Giovani Anastasi obtuvieron estelas en Abidos a través de agentes, las que luego fueron vendidas a particulares o subastadas en Leiden en 1828, en Londres en tre1837 y 1839 y en París en 1857. De hecho, las estelas de Abidos constituyen el mayor conjunto en las colecciones arqueológicas del Museo del Cairo y de otros museos europeos (Simpson, 1974). Prácticamente ninguna estela fue encontrada in situ, a excepción por ejemplo de la estela de Ankhu, hallada por el equipo de PennsylvaniaYale en 1969 (O’Connor, 1969; Simpson, 1974).

De las cientos de estelas encontradas a fines del siglo XIX, sólo unas doce, además de la estela 20570 que nos ocupa, fueron identificadas en el área denominada por Mariette como "Abidos, circunvalación/recinto norte, Kom el-Sultan". Esta zona era cercana al templo de Osiris y a un espacio elevado denominado "Terraza del Gran dios" $(r d w n$ ntr (3), que ya aparece mencionado en algunas estelas de la dinastía XI y que era donde se encontraban las capillas funerarias. 


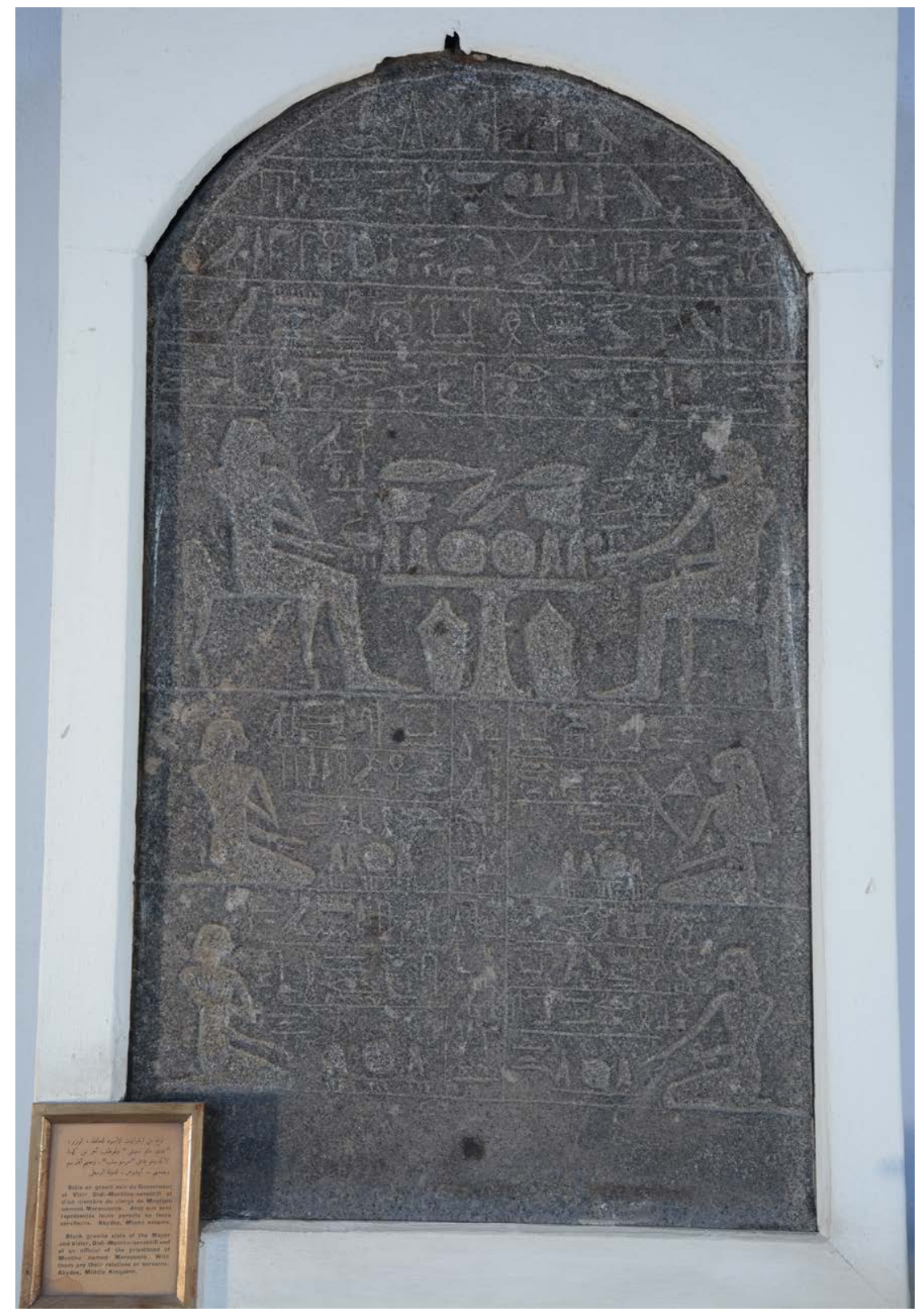

Figura 1. Estela CG 20570. ๑ Museo Egipcio de El Cairo. Foto reproducida con el permiso y la cortesía del Museo.

De la dinastía XII en adelante, capillas colectivas fueron construidas para familias o colegas para albergar estatuas, mesas de ofrendas y estelas (Bourriau, 1991). Es probable que la estela 20570 formara parte de la capilla de ofrendas que pertenecía a la familia, y la estatua que también la integraría se halla en el Museo del Cairo catalogada como CG 427 (Borchardt, 1925, pp. 32-33, pl. 69).

Kelly Simpson estudió los "lugares de ofrendas" de los funcionarios privados en Abidos durante las dinastías XII y XIII y en particular identificó los componentes de capillas de más de un individuo conectadas por relaciones familiares. A este conjunto de más de 60 capillas de ofrendas del norte de Abidos las identifica con las siglas ANOC. Este conjunto arqueológico de índole funeraria podía estar compuesto por más de una estela, estatuas y mesas de ofrendas. La estela 20570 y la estatua CG427 son agrupadas por 
Simpson en el conjunto ANOC 51 y publica fotos en blanco y negro de ambas (1974, pl. 69). No obstante, la naturaleza específica de esas "capillas" no es tan obvia a partir de la evidencia disponible (Simpson, 1974; Snape, 2019).

David O'Connor, basándose en los resultados de sus excavaciones con la Expedición de Pennsylvania-Yale en Abidos, localiza un grupo de capillas preservadas bajo el tardío portal del templo de Ramsés II, que estaba construido inmediatamente al oeste de Kom el-Sultan, adyacente del templo de Osiris del Reino Medio (O'Connor, 1985, 2009; Snape, 2019). Se trataba de estructuras relativamente pequeñas de adobe, aunque podían variar bastante de tamaño, orientadas de cara hacia el este, es decir hacia el oeste del templo de Osiris (PoulsWegner, 2012). Asimismo, logra establecer una distinción espacial entre las capillas-tumbas y las capillas o cenotafios llamados maHat (Kemp, 1975; Snape, 2011) siendo que las primeras se hallaban preferentemente en el llamado "Cementerio Norte", mientras las segundas en el área sobre el promontorio con vistas al templo de Osiris (O’Connor, 1985; Snape, 2019).

En Abidos estas capillas privadas constituían la unión perpetua de las familias con el dios Osiris, cuyos misterios y rituales se celebraban en la ciudad (Simpson, 1974). De este modo, Abidos se convirtió en el principal centro ceremonial en honor al dios durante el Reino Medio y una vía procesional recorría desde la zona norte hasta Umm el-Qab, el cementerio de las primeras dinastías, donde se consideraba estaba la tumba de Osiris. De algún modo conmemoraban la recuperación de la vida del dios después de haber sido asesinado por el dios Seth. Durante la gran procesión la figura de Osiris era transportada en la barca neshmet del templo del dios hacia Umm el-Qab, designado Poker en los textos. Algunas referencias a los "misterios" pueden encontrarse en las inscripciones de las propias estelas, así como también en la llamada "fórmula de Abidos" (Lichtheim, 1988), donde se menciona la participación o el deseo de participar en el culto de Osiris y también en la llamada "Apelación a los vivientes", que es un pedido de provisión de ofrendas (Rosell, 2018). La estela 20570 no contiene tales pedidos o deseos.

No obstante, es innegable el deseo de estar cerca de los dioses y participar del festival y ese objetivo se materializaba en una estatua y una estela que fueron erigidas para que la familia estuviera presente en el lugar del peregrinaje (Assmann, [2001] 2005a; Snape, 1994; Yamamoto, 2015). La adoración de los ancestros implicaba la potencial interacción entre vivos y difuntos y el espacio liminal no sólo estaba confinado a las capillas, ya que podía extenderse a los patios (Harrington, 2013).

Actualmente, la estela 20570 está expuesta en el Museo del Cairo EMC R21-E1-b y hemos obtenido el permiso de las autoridades de dicho museo para publicarla. Uno de los objetivos de este trabajo es ofrecer una traducción completa de la estela CG 20570, lo cual se liga a la necesidad de publicar documentos inéditos en el campo de la egiptología. Siguiendo a Detlef Franke (2002, pp. 7-8), quien afirma que "las estelas del Reino Medio son una masa de signos y símbolos, son una manifestación de códigos culturales conscientes e inconscientes y de intenciones deliberadas y acuerdos entre el/los propietarios y el artista", entendemos la importancia de interpretar y "descifrar" tales códigos. Más aún, involucran diversas materialidades en el paisaje particular de Abidos, tales como las prácticas rituales y la injerencia de agentes humanos y divinos, así como su inclusión en un espacio procesional. Este trabajo tendrá también por finalidad analizar dichas materialidades con el fin de contribuir al conocimiento de la diversidad de aspectos y facetas del paisaje epigráfico de Abidos.

\section{Epigrafía e iconografía en la estela 20570}

La estela tiene la luneta redondeada, es de granito negro y mide 87,5 centímetros de alto $x 51$ centímetros de ancho (Lange y Schäfer, 1908). Podemos identificar un primer 
registro superior con cinco líneas horizontales de texto (Figuras 2 y 3 ). No obstante, este registro podría subdividirse a su vez en dos en función de que en una misma línea se escribe un texto de izquierda a derecha y otro de derecha a izquierda sin ninguna marca de separación. En la primera línea se escribe en forma especular la fórmula de ofrenda htp di nsw "una ofrenda que el rey da": en el centro se escribe el $n s w$ "rey" y a cada lado el htp "ofrenda", incluyéndose el verbo di "da" sólo del lado izquierdo. Es decir que, la fórmula completa se desarrolla hacia la izquierda donde se menciona a Osiris, mientras que a la fórmula del lado derecho le falta el verbo "da" donde se nombra a Anubis. Podríamos especular que la ausencia del signo jeroglífico pueda deberse a un error de cálculo del escriba. No obstante, que se incluya en la fórmula del lado izquierdo asociada a Osiris y al visir Dedumontu Senebtyfy, personaje principal del monumento, nos permite suponer que se trató de una decisión calculada.

En el segundo registro se encuentran, como ya adelantamos, Dedumontu Senebtyfy y Nesmontu Seneb sentados frente a frente, en un tamaño algo mayor que los otros participantes de la estela. Dedumontu Senebtyfy sentado del lado izquierdo está sobre una silla con patas de león, presentando el brazo izquierdo flexionado sobre el pecho y el derecho sobre la mesa de ofrendas. Nesmontu Seneb, sentado sobre la derecha en una silla parecida, estira la mano derecha hacia la misma mesa mientras en la izquierda parece sostener una tira de tela plegada. Si bien esta tela no es evidente, puede deducirse si se compara con otras imágenes en estelas del período, donde el representado tiene la mano en esa posición, sosteniéndola.

Una línea vertical de texto se halla delante de cada uno. Los gestos específicos que realizan estos agentes intervinientes deben ser tenidos en cuenta como indicadores semióticos (O'Neill, 2015). En este sentido, se ha interpretado que las palmas de la mano hacia arriba mostrarían que el difunto requiere ofrendas (Franke, 2002; Harrington, 2013); en tanto, el gesto hacia abajo se trataría de una expresión de respeto o de adoración a las divinidades o al rey, aunque probablemente signifique también un pedido de provisión de ofrendas de comida (El Khadragy, 2001; O'Neill, 2015). En esta estela, los difuntos son representados sólo realizando este último gesto, con los brazos extendidos y las palmas de la mano hacia abajo; sin embargo, Hebgeget /It, su madre, parece extender su brazo con la palma hacia arriba.

La mesa de ofrendas es el punto focal en esta estela y en la mayoría de los monumentos funerarios y de culto (Bolshakov, 2001). La disponibilidad de bienes y el mantenimiento a través de ofrendas rituales se constituye en la primera materialidad en el paisaje funerario. De acuerdo a los textos funerarios reales los dioses beben cerveza y vino y comen carne, uvas e higos; los difuntos desean beber y comer al igual que ellos (Robins, 2016). Sobre la mesa que comparten los agentes principales se representan cebollas de forma simétrica arriba de toda la pila; debajo de éstas, en el centro, melones (cucumis melo) que a menudo son identificados como pepinos, pero éstos no serían conocidos hasta el período grecorromano (Nicholson y Shaw, 2000; Robins, 2016); en la base de la pila, aparecen panes de distintos tipos, y debajo de la mesa dos enormes vasijas. Sólo se adivinan las formas de los bienes. Fue de mucha ayuda para identificarlos el trabajo de Robins (2016). La relación simbólica e iconográfica de estos bienes cobra significados en el contexto de un monumento de culto; si consideramos por ejemplo las cebollas sabemos que fueron representadas también en listas de ofrendas y en el ritual de ofrendas de los Textos de las pirámides (Hays, 2006; Robins, 2016).

Como vemos, distintas capas de significado rodean la mesa de ofrendas. La escena del difunto frente a una mesa de ofrendas con alimentos no debe en modo alguno comprenderse como un documento completo y transparente. Si bien ha sido considerada como el símbolo de continuidad del ritual de ofrendas, no debe perderse de vista que como imagen despliega oposiciones binarias a través de todo el espacio figurativo (Tefnin, 


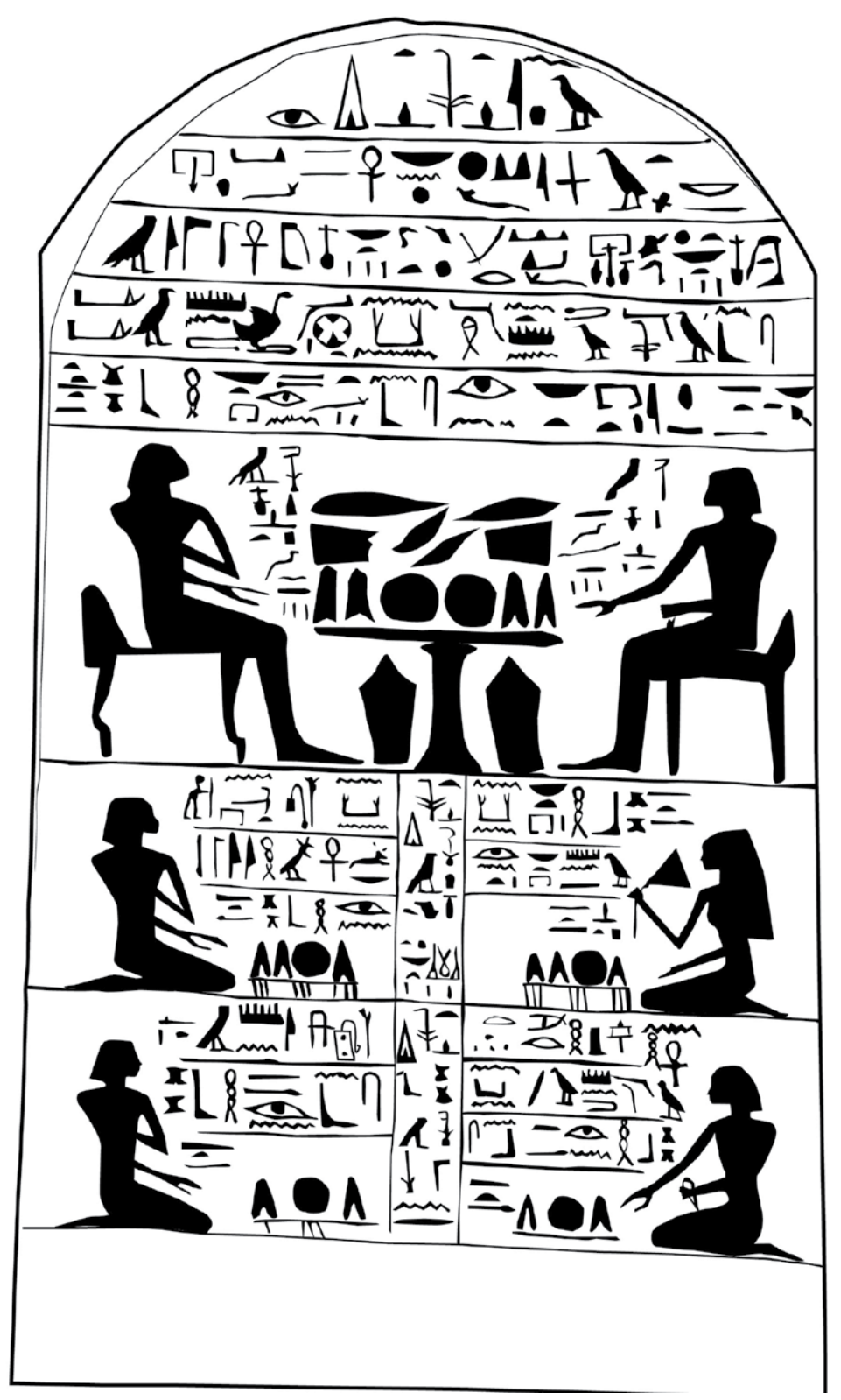

Figura 2. Estela CG 20570 del Museo Egipcio de El Cairo. @ Dibujo de Eva Calomino.

1979). Así, esta imagen de Dedumontu Senebtyfy y Nesmontu Seneb sentados no debe considerarse como un documento narrativo lineal. Aunque podrían reconocerse distintos niveles narrativos, la dificultad mayor es que no existirían reglas de desciframiento. Más aún, muchos de los significados no son del todo accesibles para nosotros hoy.

Hasta hace poco los estudios sobre la mesa de ofrendas se abordaban desde una perspectiva occidental. Por ejemplo, Pflüger (1947), uno de los primeros en abordar la temática de estas mesas, las consideraba como eminentemente seculares. Hoy hay bastante acuerdo en comprender esta escena como un motivo iconográfico multifacético y ligada a la eficacia del ritual ( $\mathrm{O}^{\prime}$ Neill, 2015). En cierto modo, a través de la mesa de ofrendas le era posible al difunto el ingreso y la permanencia efectiva en el Mas Allá. De esta manera, su inclusión en el patio de las tumbas la volvía un espacio liminal de comunicación entre los difuntos y los vivos (Harrington, 2013). 


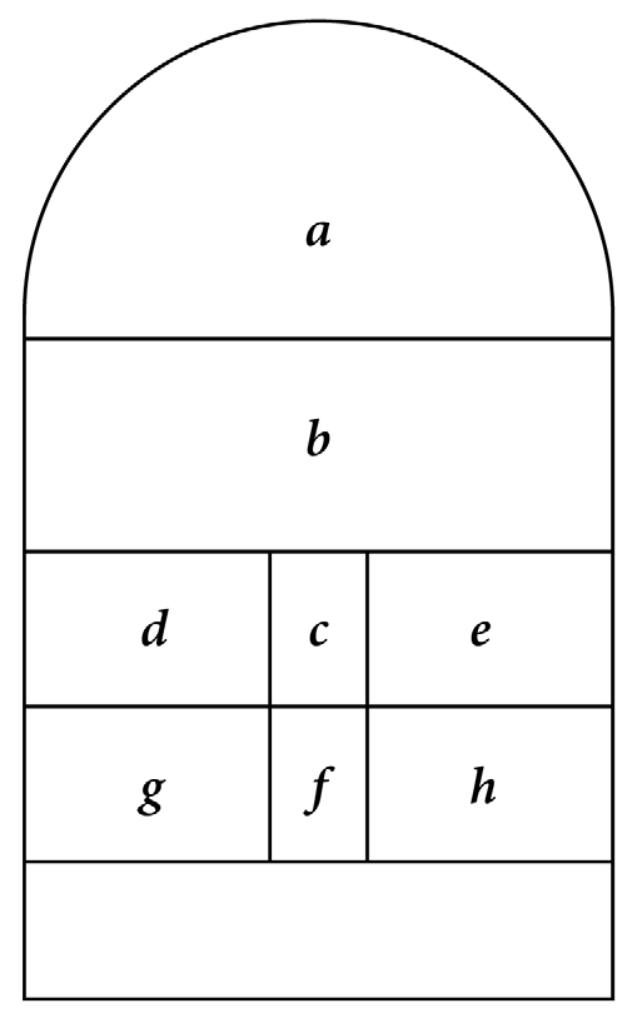

Figura 3. Esquema a partir de Lange y Schäfer (1908, p. 208).

El proceso transicional era complejo e involucraba distintas etapas de separación y por ello requería del poder regenerativo del ritual para hacer efectivo el pasaje y la transfiguración (van Gennep, [1969] 2008). No obstante, el difunto seguiría perteneciendo a la comunidad de los vivos en la medida que le fueran dadas sus ofrendas, pues las necesitaba además para seguir perteneciendo a ella. La ejecución del ritual "activaba" la presencia del difunto y a través de la recitación de las fórmulas y la materialización de las ofrendas aseguraba su permanencia. Pero no se trataba tan sólo de su memoria individual, del recuerdo de ese individuo, sino más bien del entretejido entre las tradiciones, en este caso funerarias, y de las tantas memorias individuales que constituyen la memoria colectiva (Halbwachs, [1925] 2004; Jelin, 2002) y la memoria social.

La epigrafía del paisaje funerario involucra cierta jerarquía y estatus de clase. Por ejemplo, a través del buen aspecto de los representados y de verse ataviados para la ocasión se indica su posición social pero, a pesar de que en la estela 20570 sólo puede observarse el recorte de las siluetas sin demasiados detalles de sus adornos y sus vestidos nobles, se refuerza y queda develada su condición privilegiada gracias a los títulos que se escriben junto a Dedumontu Senebtyfy y Nesmontu Seneb y el resto de los representados, claramente, con la intención de resaltar nociones de estatus e identidad (Robins, 2016). A través de las imágenes, la memoria del difunto y su rango distinguido se mantiene entre los vivos.

Los registros siguientes se disponen en cuatro cuadrantes con dos registros de textos verticales entre ellos. En cada cuadrante se halla una persona sentada sobre sus talones mirando hacia el centro. Delante de cada persona hay una pequeña mesa de ofrendas con panes y sobre ella una inscripción identificatoria del personaje. En el lado derecho superior se halla la única mujer representada en la estela, quien porta una flor de 
loto que lleva hacia su cara. Es típico en las escenas funerarias que el difunto y otras personas representadas lleven en sus manos o en sus cabezas o estén oliendo una flor de loto o nenúfar. El nombre de la mujer es Hebgeget y sabemos que es la madre del visir Dedumontu Senebtyfy porque así se menciona en el segundo registro. A partir de la estatua del visir Dedumontu Senebtyfy (Cairo CG 427), ya aludida, es posible saber que Hebgeget, su madre, también lleva el nombre de It (Vernus, 1986) y con este nombre se identifica a la madre de Nesmontu Seneb en la estela que estamos analizando (CG 20570). Esta información nos permite confirmar que los nombres It y Hebgeget pertenecen a una sola mujer y que era la madre de ambos. El nombre de Hebgeget se encuentra en otros monumentos: una estatua de granito gris en estado fragmentario (la parte superior está desaparecida) descubierta en 1905 y catalogada en el Museo del Cairo como CG 42048 (JE 37997, Legrain, 1906); una estela de luneta redondeada también del Museo del Cairo CG 20477 perteneciente a Mentuhotep, Escriba de la Gran Prisión (Lange y Schäfer, 1908; Vernus, 1986). Puede resultar extraño que se colocara en un mismo monumento dos nombres distintos a una misma persona. Más aún, que se asignen a la misma madre de los hombres representados en un mismo plano, aunque en este caso Vernus (1986) argumenta que se trata de una cuestión de simetría. Podría sugerirse también un juego con los nombres (W. Grajetzki, comunicación personal, 2019).

Los dos representados del lado izquierdo se encuentran en la misma posición que el visir Dedumontu Senebtyfy, con un brazo estirado hacia la muy baja mesa de ofrendas y el otro flexionado hacia su pecho. El otro hombre en el cuadrante inferior derecho está en la misma posición que Nesmontu Seneb: el brazo derecho estirado sobre la mesa y el izquierdo con la tira de tela. Este paralelismo entre estos dos representados es significativo, dado que reciben el mismo nombre. El último Nesmontu Seneb destaca su filiación con Hebgeget y el Nesmontu Seneb sentado en la mesa central con It, el otro nombre de la misma madre. Cabe preguntar si podía tratarse del mismo Nesmontu Seneb, que esté dos veces representado, afiliado en cada caso a uno de los nombres de la madre. Además, ella está representada entre la figura superior y focal de Nesmontu Seneb y la figura inferior del representado con el mismo nombre, por lo que podría tratarse de otro juego figurativo.

\section{Las inscripciones}

a. Línea 1:

wsir hitp di nsw htp inpw

1. El topónimo Ankhtawy “vida de las Dos Tierras" se localiza en la región menfita. Es posible sugerir que el paisaje evocado por el topónimo Ankhtawy podría haber sido proyectado en el entorno de Abidos donde la procesión anual de Osiris se realizó (Borrego Gallardo, 2017-2018; Spiegel, 1973). No obstante, Borrego Gallardo considera que el topónimo hace referencia al Wadi Abusir y no a la ciudad de Menfis y su necrópolis durante este período.

2. Epíteto del dios Anubis que a menudo se traduce "el que está en la sala/tienda del embalsamamiento". Véase DuQuesne (2012); Logan (1990); asociado al ritual del embalsamiento Köhler (1980). Asimismo, puede referir a un topónimo (Gauthier, 1925).

Osiris Una ofrenda que da el rey a Anubis

\section{a. Línea 2:}

nb `nh t3wy di.f prt hrw

Señor de Ankhtawy. ${ }^{1}$ Él da

ofrendas de invocación.

\author{
a. Línea 3: \\ ihw 3pdw ht nbt nfrt w'bt ${ }^{\top}$ hl ht ntr im \\ ganado y aves, y todas las cosas \\ bellas y puras por las que el dios vive.
}

tp $d w$. f imy wt $n b d s r t$

Sobre su montaña, el que está sobre el $\mathrm{wt}^{2}$, señor de la Tierra Sagrada. di.f prt hrw t hnkt ịhw 3pdw hnt nbt nfrt w'bt Él da ofrendas de invocación, pan, cerveza, ganado y aves, y todas las cosas bellas y puras. 
a. Línea 4

imy-r niwt t3ty $d d w$ mntw

Para el $k a$ del superintendente de

la ciudad, visir, Dedumontu ${ }^{3}$

$n k 3 n$

imy-r šnt ns mntw snb [mวّ hrw]

Para el $k a$ del superintendente

de las disputas la Nesmontu

Seneb [justo de voz], ${ }^{4}$

ir n nbt pr it m3 hrw nbt im 3hww nacido de la señora de la casa It, ${ }^{5}$ justa devoz, señora deveneración.

Senebtyfy, justo de voz, nacido de la señora de la casa Hebgeget, ${ }^{6}$ justa de voz.
3. Ranke (1935, p. 402, 19); lo identifica en este monumento.

4. Ranke (1935, p. 312, 15).

hb- $m$ htpt $\underline{d} f 3$

ḩ了-m t ḥnkt ḥtpt $\underline{d} f 3$

miles de ofrendas de comida.

5. Ranke (1935, p. 49, 3).

6. Ranke (1935, p. 236, 23); lo identifica en este monumento.

b.

miles de panes, cerveza,

ofrendas de comida.

c.

$h t p d i \quad$ Una ofrenda que el

nsw h3 $\quad$ rey da: miles de

$t$ hnkt panes, cerveza

$i h w 3 p d w \quad$ ganado, aves,

ss alabastro,

mnht ropa,

ht $n b t \quad$ y toda cosa.

d.

$n k 3$ š̌ hnrt wr

Para el ka del escriba de la gran kheneret,

iwr-`nh (¿?) nhy ir n ḥbggt me hrw

Iwr-ankh ${ }^{7}$ Nehy, ${ }^{8}$ nacido de Hebgeget, justa de voz

7. Seguimos a Vernus (1986, p. 6, 10) aunque, como él también admite, se observa en la figura iw $n b$ ` $n h$.

e.

8. Ranke (1935, p. 207, 15).

$n$ k’ $n$ nbt pr hbggt m` hrw

Para el ka de la señora de la casa, Hebgeget, justa de voz.

irt $n$ nbt pr mntw htp $m 3^{\complement}$ hrw

Nacida de la señora de la casa, Montuhotep, ${ }^{9}$ justa de voz.

9. Ranke (1935, p. 154, 21).

f.

htp di nsw Una ofrenda que el rey da

gb a Geb


hl $m$ sntr $\quad$ miles de incienso.

10. Ranke (1935, p. 28,13$)$ incluye el nombre compuesto.

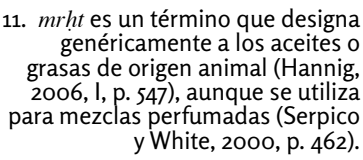

\section{g.}

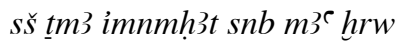

El "escriba del catastro", Amenemhat Seneb, ${ }^{10}$ justo de voz.

ir n ḩbggt m" hrw

Nacido de Hebgeget, justa de voz.

\section{h.}

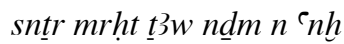

incienso perfumado, ${ }^{11}$ para respirar el dulce aliento de vida.

$n k 3 n$ whmw ns mntw

Para el ka del "reportero" Nesmontu

snb m³ hrw ir n hbggt m3 hrw

Seneb, justo de voz, nacido de Hebgeget, justa de voz.

\section{Fórmula de ofrenda: reactualización ritual y materialidad}

Lo que los egiptólogos denominan fórmula de ofrenda se encuentra en la mayoría de las estelas del Reino Medio, además de en otro tipo de soportes como ataúdes y muros de tumbas. Pueden encontrarse variantes desde su primera aparición en la dinastía IV hasta el período romano. Aparece por primera vez en el Reino Antiguo, primero en el arquitrabe o las jambas de las falsas puertas, después en las mesas de ofrendas, los ataúdes, las estatuas y finalmente es incorporada en las estelas funerarias y conmemorativas.

Involucra cuatro partes (Allen, 2014): 1) htp di nsw "una ofrenda que da el rey", que coloca al rey en el centro de la ritualidad y como máximo dador entre los dioses. No obstante, la ofrenda del rey era dada por una fundación funeraria local y no por el propio rey. 2) A continuación la fórmula nombra al dios o a los dioses de tales fundaciones, comúnmente Osiris o Anubis, como intermediarios o agentes de la ofrenda; en nuestro caso a los dos: Osiris y Anubis, con sus epítetos. Nótese que cuando la fórmula se repite en la inscripción (f) se nombra a Geb, aunque la inclusión de este dios en las fórmulas no es tan frecuente. 3) Los llamados requerimientos o peticiones di.s/f/sn Ella/ Él/ da o /Ellos dan, que es una innovación de la dinastía XII, con los nombres de los receptores de los favores requeridos: "Qué él pueda dar una invocación" (Bennett, 1941, p. 78; Gardiner, [1927] 1988, p. 171). Claramente, se refiere al dios, porque cuando se trata de una diosa, la menciona, ej: Maat y Hathor. Literalmente significa "la salida de la voz", porque implicaba la recitación en voz alta por el dedicante y se convertía así en un acto mágico-evocativo. En la estela que estamos analizando se incluye el di.f "Él da", en ambos textos asociados a Osiris y a Anubis. Luego sigue la lista de ofrendas. 4) La última parte de la fórmula se dedica "al $k a$ del" $-n k 3 n$-difunto propietario del monumento y se inscribe su nombre, títulos y el $m 3$ - hrw "justo/a de voz", traducido también como justificado/a. Esta última frase alude al requerimiento del difunto de ser juzgado y tener éxito en ese proceso, pudiendo estar en armonía con los principios de maat, el orden natural del universo.

De acuerdo a Bennett (1941), quien a partir de 121 estelas establece 11 criterios de datación, tales como el uso de ciertos determinativos y frases formularias para 
diferenciar las inscripciones en las de la dinastía XI, temprana XII y tardía XIII, y también a Satzinger (1997), pueden encontrarse variaciones respecto del htp di $n s w$. En textos del Reino Antiguo se utilizan cláusulas paralelas para introducir al rey y a los dioses: "Una ofrenda que el rey da...y una ofrenda que Anubis/Osiris/Geb da..." (Gardiner, [1927] 1988). De acuerdo a esta fórmula, el rey y el dios son los donantes. Posteriormente, el oferente es sólo el rey, como Horus, como hijo y heredero de su padre Osiris. Por tanto, se ha comprendido que después del htp di nsw "una ofrenda que el rey da" y antes del nombre del dios debe incluirse la preposición $n$ "a". Así el dios sería el receptor de tal ofrenda (Gardiner, [1927] 1988; Lapp, 1986; Satzinger, 1997). Con diferente opinión, Franke (2003, p. 40, n. 4) cuestiona el método de Bennett y sostiene el uso de una serie diversa de monumentos donde se encuentra la fórmula. Asimismo, considera que las diferencias regionales no son tenidas en cuenta a la hora de establecer los criterios. El período considerado no se extiende más allá de la dinastía XII, dejando fuera de la muestra a la dinastía XIII.

Del mismo modo, Allen (2014, p. 374) ha alegado a favor de una fórmula en la que tanto el rey como el dios son los oferentes, resultando en "una ofrenda que el rey da y el dios da", siguiendo la tradición del Reino Antiguo. No obstante, Allen enfatiza la función de los dioses como agentes de la ofrenda. También véase el trabajo de Willems (1991), que cita incluso la estela 20570.

En la estela que nos ocupa (20570) la primera fórmula "una ofrenda que el rey da" (a. l. 1) es compartida, como hemos expresado, por Osiris y Anubis. No obstante, le siguen requerimientos para cada uno de los dioses y vinculados a los receptores de los favores que son dos: Dedumontu Senebtyfy y Nesmontu Seneb. Los agrupamientos espaciales permiten suponer que Dedumontu Senebtyfy lo recibe de Osiris y Nesmontu Seneb de Anubis. La segunda fórmula "una ofrenda que el rey da" (c) no explicita el nombre del dios, aunque los receptores de los favores son Hebgeget y Iwr-ankh Nehy. La tercera fórmula "una ofrenda que el rey da" (f) está asociada al dios Geb y, espacialmente, se liga a Amenemhat Seneb y a Nesmontu Seneb.

Esta descripción formularia puede ser interpretada como la tradición de reversión de las ofrendas (Umlaufopfer): el rey entrega ofrendas de comida a los dioses y después que están satisfechos, las ofrendas pasan desde los altares de los dioses a las estelas de ofrendas o a las estatuas para alimentar a sus propietarios. Es posible que las ofrendas provinieran de los dominios de culto real para presentar a los dioses, es decir, como donaciones a las instituciones de culto local (Assmann, [1996] 2005b). Por otra parte, la provisión al $k a$ del difunto se vincula al propio monumento y a la necesidad de proveerlo con comida y bebida, lo cual implicaba acciones de tipo material y funcional (Snape, 2011).

El hecho de que estas fórmulas de ofrendas sean una clase de textos muy estereotipada y generalizada a menudo supone una estructura repetitiva y mecánica de carácter funcional. La propia composición formularia responde a un imperativo de repetición ritual para garantizar la coherencia ritual (Assmann, [2005] 2011). Jan Assmann (1992, p. 87) argumenta acerca de un proceso de "semiosis sagrada", basado en la triple distinción:1) Acción, 2) Representación icónica y 3) Recitación. Así, los textos y las imágenes tienen un fuerte simbolismo estereotipado, a primera vista, porque están anclados en su carácter sagrado e invariable.

El propio proceso de transmisión de la celebración ritual se realizó en forma de repetición, reproduciendo un orden dado sin cambios en la medida de lo posible. Como aclara Assmann ([2005] 2011), no se agotan en la repetición, en la mera reiteración de un decurso establecido: actualizan también un sentido, aunque siempre garantizando la continuidad y la identidad cultural. Assmann (2010) también señala 
que todos los rituales combinan dos elementos: de repetición y de presentificación; cuanto más rígidamente se apegan a un orden establecido, más predomina el aspecto de la repetición.

La imagen, por otra parte, no debe engañarnos sobre el carácter performativo de la acción ritual que estamos observando. Los ritos se repiten en textos, de modo que las palabras escritas y pronunciadas contienen un poder mágico para asegurar el suministro permanente de ofrendas. Si las ofrendas de comida cesaban, la fórmula de ofrenda garantizaba mágicamente la provisión permanente de comida y la asistencia de los sacerdotes funerarios para lograrlo.

Todo el culto egipcio se basa en las dos dimensiones de la repetición ritual y de la actualización mítica a través de la interpretación sacramental. En particular, las representaciones funerarias no-reales contienen tres elementos "estereotipados" o más bien necesariamente repetitivos: ritualistas, listas de ofrendas y el difunto en la mesa de ofrendas (Hays, 2011). En la estela Cairo 20570 no se representan los ritualistas, pero alguien debió estar a cargo de la recitación de las fórmulas.

Con todo podemos distinguir entre las ofrendas en la mesa y aquéllas pronunciadas en la performance ritual. Las ofrendas en la mesa incluyen bienes tales como melones y cebollas, que no forman parte de las ofrendas de las inscripciones para ser recitadas. Asimismo, bienes como ganado, aves, ropa, alabastro e incienso no son incluidos en la mesa.

Para Dedumontu Senebtyfy se listan: ganado (a l. 3); aves (a l. 3); panes (b); cerveza (b); provisiones de comida (b).

Para Nesmontu Seneb se listan: pan (a l. 3); cerveza (a l. 3); ganado (a l. 3); aves; (a l. 3) provisiones de comida (b).

Iwr-ankh Nehy y Hebgeget comparten: panes; cerveza; ganado; aves; alabastro; ropa (c).

Amenemhat Seneb y Nesmontu Seneb comparten incienso (f) y Nesmontu Seneb también recibe incienso perfumado $(\mathrm{h})$.

En suma, el ritual de ofrendas provee con eficacia al difunto de la comida de los dioses, y la materialidad de las ofrendas la garantiza.

\section{La datación}

A partir de ciertos componentes de la fórmula de ofrenda, además de aspectos paleográficos, epigráficos y rasgos artísticos, la estela puede ser datada a finales de la dinastía XII o dinastía XIII. En general, los investigadores acuerdan en considerar que el período conocido como Reino Medio puede dividirse entre temprano y tardío. No obstante, algunos estudiosos consideran que la dinastía XIII podría encuadrarse en el Reino Medio, mientras otros sostienen que debería considerarse en el marco del Segundo Período Intermedio (Grajetzki, 2013a). Los primeros se basan en que no hay una ruptura visible entre las dinastías XII y XIII. En consecuencia, la estela que estamos considerando podría caer en una u otra. La historia política de la dinastía XIII se caracteriza por una sucesión de reinados cortos y por ello el segundo grupo la excluye del período de centralización política conocido como Reino Medio.

Es cierto que el sistema de datación de las estelas, en particular el utilizado por Bennett, ha sido caracterizado como estadístico mecanicista; sin embargo, tomando 
en consideración ciertos componentes de la fórmula de ofrendas, se puede establecer una datación aproximada. Los criterios utilizados han sido la escritura del nombre del dios Osiris con el asiento portátil y el ojo $\mathcal{A}$, sin determinativo, que comienza a utilizarse a partir del reinado de Sesostris III. Antes de ese reinado el nombre del dios se escribe con el asiento 』] (Q1) (Bennett, 1941) y en lugar del signo del asiento Q1 a partir del reinado de Amenemhat IV (Ilin-Tomich, 2017). Del mismo modo, a partir del reinado de Sesostris III se utilizó "al ka del" $-n k 3 n$ - eliminándose "del venerado", designación del difunto encontrada desde la dinastía XI en la fórmula.

Por otra parte, Ilin-Tomich $(2011,2017)$ señala que habiendo estudiado 243 estelas de la dinastía XII previas a Sesostris III no encontró escrito |ð| š̌ mnht "alabastro y ropa" con esta forma combinada, aunque éstos eran elementos comunes incluidos en la ofrenda. Del mismo modo, la inclusión de la frase $t 3 w n$ ' $n h$ "aliento dulce de vida" es otra de las razones para datarla en ese período. La restauración del aliento es fundamental en el proceso de transfiguración, es decir, adquirir el estatus de $a k h$, en la fórmula de ofrenda de la dinastía XII tardía o mediados de la dinastía XIII (Whelan, 2016).

Las figuras de Dedumontu Senebtyfy y Nesmontu Seneb se representan del mismo tamaño y las figuras de su madre y hermanos son similares en postura y aspecto (Bright, 2005; Müller, 1933), a diferencia de las estelas del Reino Medio temprano, donde se colocaba, como ya mencionamos, a la familia y servidores en un plano secundario (Grajetzki, 2007). Otro motivo iconográfico que permite establecer esta datación es que Hebgeget está sentada sobre una rodilla y éste es un motivo cotejable exclusivamente en otras estelas de este período (Bright, 2005; Leprohon, 1996).

El deterioro de la calidad de ejecución es otro aspecto que ubica a la estela a fines de la dinastía XII o en la dinastía XIII (Bright, 2005; Evers, 1929). La datación basándose en el estilo ha sido abordada por Ilin-Tomich (2017), quien realiza un estudio diacrónico comparativo, sugiriendo que nuevos rasgos se propagan rápidamente en diversos centros de producción. Asimismo, examina el origen extra-abideno de las estelas encontradas en el sitio, concluyendo que una importante proporción de estelas del tardío Reino Medio fueron producidas en talleres en centros claves como Tebas y Menfis y llevadas luego a Abidos. Freed (1996) define un taller como un grupo de tres o más estelas que comparten aspectos distintivos, aunque su estudio se enfoca en la evidencia de principios de la dinastía XII.

\section{Los agentes humanos intervinientes: títulos y epítetos}

Ya hemos mencionado los agentes divinos intervinientes en el paisaje de Abidos. A continuación nos enfocaremos en los agentes humanos representados y su adscripción social, descripta a partir de sus títulos.

Dedumontu Senebtyfy, como adelantamos, porta el título de visir — $t 3 t y$-, además del de "supervisor de la ciudad" - imy-r niwt- (Hannig, 2006; Ward, 1982). Desde el Reino Medio estos títulos fueron llevados conjuntamente (van den Boorn, 1988) de manera permanente (van de Walle, 2013) e implicarían las funciones del visir como gobernante de la ciudad capital (Hari, 1965). De hecho, de acuerdo a Gardiner (1947, p. 24) sería un vestigio del título del Reino Antiguo: "gobernador de la ciudad de la pirámide".

El papel del visir en la segunda mitad de la dinastía XII parece haber sido crucial (Eyre, 2013; Westbrook, 2003). Es probable que el visir nombrara a los portadores de los títulos de la administración en el nivel local (Grajetzki, 2013b). Entre sus atribuciones se destacan la organización de la mano de obra, la disposición de trabajos públicos y 
el mantenimiento de las leyes. Respecto de la disposición de las leyes, puede haberse desempeñado como consejero del rey o, como es evidente en el papiro Brooklyn 35.1446, ejecutando decretos reales. Asimismo, puede haber tenido poder de decisión sobre las conclusiones de los tribunales locales (Hayes, 1955).

La evidencia de dos visires actuando al mismo tiempo en el Reino Medio tardío es inconsistente (Grajetzki, 2013b; Quirke, 2004). Es probable que existieran distintas oficinas del visirato a lo largo del territorio y el visir actuara a partir de sus funcionarios allí apostados. Como fuere, el papel del visir fue muy significativo en este período e incluso Habachi (1984) afirma que ciertos visires de la dinastía XIII provenían de familias poderosas favorecidas por el rey al que servían.

Nesmontu Seneb porta el título "superintendente de las disputas" - imy-r r šnt-. Este título es bastante frecuente en el Reino Medio y sobre el mismo es posible encontrar diversos comentarios e interpretaciones y no es unánime su enunciación (Andreu, 1991; Quirke, 2004; Ward, 1982, entre muchas otras). Se ha interpretado que el título debe traducirse como "superintendente de las disputas", pero también "jefe de la policía" o "jefe sheriff". El alcance de las funciones de las personas que lo portaban no está demasiado claro, incluso se lo ha ligado a tareas de repostaje. En el Reino Medio, pueden haber realizado trabajo policial en centros urbanos y en las áreas del desierto, siendo responsables del mantenimiento del orden, actuando en la gestión de querellas y en interrogatorios policiales. Posteriormente, desarrollaron sus funciones en el área de los templos. Andreu (1991) distingue entre las funciones en el Primer Período Intermedio, cuando debían hacer respetar la ley en cada aldea, de las funciones del Reino Medio, cuando era una especie de comisario judicial, que debía arrestar y juzgar a los ladrones, dirigir las investigaciones e instruir los procesos judiciales. Probablemente, actuaba en casos más graves o excepcionales y pudo tener injerencia y atribuciones en materia criminal (Quirke, 2004).

Grajetzki (2013b) menciona el título, considerando que si bien no es de rango, debería estar ligado a la administración central. Sus funciones pueden haber estado vinculadas al $p r$ - $n s w$, la casa del rey y estaría a cargo de informar al visir sobre el trabajo de control policial. Por ejemplo, en los Despachos de Semna informa sobre el peligro de los nubios en la cercanía de la fortaleza de Yeken (Smither, 1945). Grajetzki (2013b) considera que pueden haber torturado personas para obtener información, desempeñándose como una especie de servicio secreto. Otra función del "superintendente de las disputas" estaba asociada a los campos hbsw, donde actuaba como representante del visir en los asuntos concernientes a este tipo de terrenos. Asimismo, el visir es el que designa al "superintendente de las disputas" en cada oficina del palacio. De este modo, Dedumontu Senebtyfy y Nesmontu Seneb estaban vinculados también por sus funciones. En la tumba de Rekhmira, un visir de la dinastía XVIII, encontramos una famosa inscripción conocida como Deberes del visir, una especie de tratado de administración, que vincula estos dos títulos: "En cuanto a todo lo que entra o sale del territorio de la Residencia, es su comisionado el que controla la entrada y la salida. Los supervisores de disputas, oficiales y supervisores de distritos le informan sobre sus asuntos" (van den Boorn, 1988). No hay acuerdo sobre la datación del texto original, pero se supone que puede haber sido escrito en el Reino Medio Tardío si nos basamos en los títulos conocidos para esa época (Grajetzki, 2013b).

Iwr-ankh Nehy tenía el título de "escriba de la gran kheneret" — š̌ $n$ hnrt wr - (Ward, 1982). La institución gran kheneret era la encargada de organizar el trabajo obligatorio (corvea o azofra) en todo el territorio egipcio y entonces proveer trabajadores temporarios para diferentes obras arquitectónicas, fundaciones funerarias, expediciones, entre otras.

No obstante, la institución tuvo probablemente un carácter coactivo y desarrolló funciones policíacas y reclusorias (Espinel, 2003; Quirke, 1988). Esta faceta compulsiva 
se hace presente en el Papiro Brooklyn 35.1446, donde aparece como un centro administrativo para albergar, disciplinar y dirigir los esfuerzos de individuos asignados a trabajo temporal o permanente (Castro, 2017; Hayes, 1955). La evidencia sobre el kheneret es de índole textual, no de registro arqueológico (Moeller, 2016).

Como "escriba de la gran kheneret" debió también cumplir sus funciones en dependencia con el visir. Asimismo, en la inscripción en la tumba de Rekhmira (van den Boorn, 1988) se explicita que los transgresores debían ser agregados al rollo de papiro que está en la gran kheneret. Contempla entre los transgresores a los ineficientes en sus misiones, de acuerdo a lo determinado por el visir en su oficina después de escuchar los casos.

Amenemhat Seneb porta el título de "escriba del catastro" — š̌ tm3-, también traducido como "escriba de la estera" (Manning, 2003). Por los libros de registro del Reino Medio sabemos que supervisado por el "jefe de los campos" registraba la inspección de las tierras locales (Eyre, 2013). Aparentemente, otros funcionarios actuaban "llevando la cuerda" o "extendiendo la cuerda". El visir era quien coordinaba tales actividades (Quirke, 1990; van den Boorn, 1988).

No obstante, el "escriba del catastro" era el funcionario principal en este procedimiento y garantizaba el éxito del mismo ya que confeccionaba las listas de registro. Más aún, podía tener la autoridad necesaria para la aplicación de la ley en caso necesario. En los Deberes del visir, del Reino Nuevo, ya mencionado, el título $\underline{d} \underline{d} \underline{d} \mathrm{t} n \mathrm{tm}$ ? se liga a la gestión de los campos con carácter jurídico en relación con el visir y el "director de los campos".

Nesmontu Seneb porta el título de "reportero" whmw (Quirke, 2004; Ward, 1982), mayoritariamente traducido como "heraldo", "registrador legal", "mediador". Literalmente, significa "repetidor" y entendemos que funcionaba como secretario que informaba al rey o a la oficina central, estableciéndose en distintas regiones (por ejemplo "segundo reportero del sur") o en ciudades. Es muy probable que sus funciones estuvieran vinculadas al visir y que incluso debiera presentar reportes a éste cuando actuaba en distintas oficinas del territorio. La oficina del reportero es citada como aquélla donde los registros públicos eran archivados (Quirke, 1990) y ello confería al reportero una autoridad administrativa muy significativa.

El título se asocia al "escriba del catastro" — $s \check{s} t m 3$-, portado en la estela por Amenemhat Seneb y también al visir Dedumontu Senebtyfy. En cada provincia un consejo de gobierno era presidido por el "escriba del catastro" que, como ya mencionamos, dependía del visir; el "reportero" era el integrante más importante de ese consejo, después del gobernador, asumiendo funciones de notario responsable del registro (Grandet, 2013b).

Como hemos señalado, podría tratarse del mismo Nesmontu Seneb representado en la estela con el mismo nombre en la escena focal frente a la mesa de ofrendas mayor. Más aún: en los Deberes del visir, el título "superintendente de las disputas" -imy-r šnt- podría estar asociado al de "reportero" - whmmw -, aunque con diferente opinión Faulkner (1955) y van den Boorn (1988).

La función policíaca del "reportero" es visible en una carta pUC 32200 35a (Autere, 2017; Collier y Quirke, 2002) donde el emisor muestra su preocupación por cómo se actuó con un ladrón en el palacio. Debería existir una oficina específica del "reportero", dado que en otra carta pUC 32209, 1.1.-1.10; 35b 2.1-2.10; vs. 1-3 (Autere, 2017; Collier y Quirke, 2002) se dice que un hombre que huyó del trabajo en los campos fue sentenciado a muerte en ella. Tortura y muerte ocurren en la oficina del "reportero". Probablemente cuando se trataba de un "reportero real" realizaban otras actividades tales como participar en la fundación de monumentos y de expediciones reales (Louvre E.17341; Urk. IV, 1484-86). 


\section{A modo de cierre}

Abidos, era un espacio sagrado dinámico con intervenciones humanas y divinas, donde acciones rituales y ofrendas materiales conectaban el mundo de los vivos y los difuntos. Los parientes mancomunados en pos del beneficio de los difuntos vuelven más complejos los roles y la iconografía de la mesa de ofrendas en el Reino Medio tardío.

Los rasgos iconográficos de la mesa de ofrenda sirven como una matriz que asegura el culto recurrente para la supervivencia del difunto en el Más Allá. Las acciones rituales involucradas en la escena y en las recitaciones colocan a su destinatario entre aquellos beneficiados con el aporte material de los dioses por su estatus social. En particular en la estela 20570 el ritual no se acompaña de acciones físicas visibles, aunque la fórmula alguien debió recitarla y las ofrendas deben haber sido dadas/colocadas por los sujetos habilitados.

Múltiples significados rodean a esta estela, que posiblemente estuviera emplazada en el paisaje funerario de Abidos. En modo alguno estos significados son unilaterales y transparentes. Los íconos y las palabras rituales confluyen en el propósito efectivo de proveer a los difuntos de comida y bebida para el Más Allá. No obstante, el carácter repetitivo y en cierto modo estereotipado de la fórmula de ofrenda remite a su carácter ritual, reactualizando de este modo una memoria mítica. La tradición funeraria en un paisaje procesional —el de la ciudad primordial que era Abidos - crea memorias colectivas y obligaciones materiales, algunas de las cuales se vuelven evidentes en la estela. Las ofrendas materiales serían requeridas de los cultos divinos a través del simbólico beneplácito real.

Las memorias individuales de los agentes representados - Dedumontu Senebtyfy, Nesmontu Seneb, Iwr-ankh Nehy, Amenemhat Seneb y la madre Hebgeget-cumplen el objetivo de crear sentido de pertenencia y se enmarcan en una memoria social, grabada colectivamente. En esta estela prácticamente carecen de narrativa, pero los títulos portados en vida por los agentes son la marca de su distinción social. Por esos títulos sabemos que pertenecían a una alta elite y por ello obtenían el beneficio de la ofrenda del rey y de los principales dioses funerarios.

El control social y policíaco que ejercieron en sus puestos se conoce por otros documentos. El visir Dedumontu Senebtyfy probablemente estaba cercano al rey y sus hermanos desempeñaron altos cargos vinculados a las funciones del visir. La filiación materna es subrayada a partir de la representación y las inscripciones de Hebgeget/It, enlazando gracias a ella a los miembros de la familia.

Por último, hemos presentado una transliteración y traducción completa de la estela CG 20570, lo que constituye un punto de partida para futuras discusiones y consideraciones acerca de, en particular, la familia del visir Dedumontu Senebtyfy, e, in extenso, de la participación de la alta elite en el paisaje funerario en Abidos.

\section{Agradecimientos}

Este trabajo fue realizado en el marco del Proyecto I+D: 11/H807: Estudios sobre las elites en Abidos a partir de las estelas del Museo de El Cairo, financiado por la Universidad Nacional de La Plata. Agradecemos a la directora del Museo del Cairo, Ms. Sabah Abdel Razek, y a la Jefa del Departamento de Registro, Gestión de Colecciones y Documentación del museo, Dra. Marwa Abdel Razek Mahmoud, por sus gestiones y ayuda. En este sentido, agradezco también al Dr. Pablo Rosell quien en enero de 2018 realizó las gestiones en Cairo ante las autoridades del Museo para la obtención de los permisos y las fotografías. Asimismo, hago extensivo mi agradecimiento a los evaluadores anónimos que contribuyeron a mejorar el manuscrito. 


\section{Q Referencias citadas}

" Allen, J. P. (2014). Middle Egyptian: An Introduction to the Language and Culture of Hieroglyphs (3를 edición). Cambridge: Cambridge University Press.

" Andreu, G. (1991). Deux stèles de commissaires de police (imy-r šnt) de la Première Période Intermédiaire. Cahiers de recherches de l'Institut de papyrologie et d'égyptologie de Lille, 13, 17-23.

»Assmann, J. (1992). Semiosis and Interpretation in Ancient Egyptian Ritual. En S. Biderman y B. A. Scharfstein (Eds.), Interpretation in Religion (pp. 87-109). Leiden: Brill.

"Assmann, J. ([2001]2005a). Death and Salvation in Ancient Egypt. Ithaca y Londres: Cornell University Press.

》 Assmann, J. ([1996]2005b). Egipto: Historia De Un Sentido. Madrid: Abada.

》Assmann, J. (2010). Cultural Memory and Early Civilization: Writing, Remembrance, and Political Imagination. Cambridge: Cambridge University Press.

》 Assmann, J. ([2005]2011). Historia y mito en el mundo antiguo. Madrid: Gredos.

"Autere, K. (2017). Normative language in the Late Middle Kingdom epistolary material from el-Lahun. (Tesis de Maestría), University of Helsinki, Finlandia.

" Bennett, C. J. (1941). Growth of the Htp-Di-Nsw Formula in the Middle Kingdom. Journal of Egyptian Archaeology, 27, 77-82.

"Bolshakov, A. (2001). Offering tables. En D. Redford (Ed.), Oxford Encyclopedia of Ancient Egypt (Volumen II, pp. 572-576). Oxford: Oxford University Press.

» Borchardt, L. (1925). Statuen und Statuetten von Königen und Privatleuten im Museum von Kairo. Berlín: Reichsdruckerei.

" Borrego Gallardo, F. (2017-2018). Ankhtawy: notes on its nature and location between the Old and New Kingdoms. Isimu, 20-21, 479-532.

" Bourriau, J. (1991). Patterns of change in burial customs during the Middle Kingdom. En S. Quirke (Ed.), Middle Kingdom studies (pp. 3-20). New Malden: SIA Publishing.

》Bright, D. (2005). Dating Funerary Stelae of the Twelfth Dynasty: A Statistical Study. (Tesis Doctoral inédita), Macquarie University, Australia.

"Castro, M.B. (2017). Persecuciones y reclusión a los trabajadores del Egipto faraónico. En C. Astarita, C. García Mac Gaw y A. Zingarelli (Eds.), Conflictos sociales en la antigüedad y el feudalismo (pp. 35-41). La Plata: Edulp.

"Collier, M.y Quirke, S. (2002). The UCL Lahun papyri: Letters. Oxford: British Archaeological Reports International Series 1083, Hadrian Books.

"DuQuesne, T. (2012). Jmjwt. En W.Wendrich (Ed.), UCLA Encyclopedia of Egyptology, https://escholarship.org/content/qt79m15oqt/qt79m15oqt.pdf?t=pls39m

»El-Khadragy, M. (2001). The adoration gesture in private tombs up to the early Middle Kingdom. Studien zur Altägyptischen Kultur, 29, 187-201.

» Espinel, D. A. (2003). Cárceles y reclusorios en el antiguo Egipto (2686-1069 a.C.). En S. Torallas Tovar e I. Pérez Martín (Eds.), Castigo y reclusión en el mundo antiguo (pp. 1-25). Madrid: Consejo Superior de Investigaciones Científicas. 
»Evers, H.G. (1929). Staat aus dem Stein: Denkmäler, Geschichte und Bedeutung der ägyptischen Plastik während des Mittleren Reichs. Munich: Bruckmann.

» Eyre, C. (2013). The Use of Documents in Pharaonic Egypt. Oxford: Oxford University Press.

» Faulkner, R. (1955).The Installation of the Vizier. Journal of Egyptian Archaeology, 41, 18-29.

"Franke, D. (2002). The Middle Kingdom Stelae Publication Project, exemplified by stela BM EA 226. The British Museum Studies in Ancient Egypt and Sudan, 1, 7-19.

» Franke, D. (2003). The Middle Kingdom Offering Formulas: A Challenge. Journal of Egyptian Archaeology, 89, 39-57.

" Freed, R. (1996). Stela Workshops of Early Dynasty 12. En P. Der Manuelian (Ed.), Studies in Honor of William Kelly Simpson (pp. 297-336). Boston: Museum of Fine Arts.

" Gardiner, A.H. (1947). AEO- Ancient Egyptian Onomastica. Oxford: Oxford University Press.

》 Gardiner, A. H. ([1927]1988). Egyptian Grammar. Oxford: Griffith Institute.

"Gauthier, H. (1925). Dictionnaire des noms géographiques contenus dans les textes hiéroglyphiques (volumen 1). Cairo: Institut français d'archéologie orientale pour la Société royale de géographie d'Égypte.

"Grajetzki, W. (2007). Multiple Burials in Ancient Egypt to the End of the Middle Kingdom. En S. Grallert y W. Grajetzki (Eds.), Life and Afterlife in Ancient Egypt during the Middle Kingdom and Second Intermediate Period (pp. 16-34). Londres: Golden House.

》 Grajetzki, W. (2013a). Late Middle Kingdom. En W. Wendrich (Ed.), UCLA Encyclopedia of Egyptology, http://digital2.library.ucla.edu/viewltem.do?ark=21198/zzoozhonhs

"Grajetzki, W. (2013b). Setting a state anew: the central administration from the end of the Old Kingdom to the end of the Middle Kingdom. En J. C. Moreno García (Ed.), Ancient Egyptian Administration (pp. 215-258). Leiden-Boston: Brill.

» Grandet, P. (2013). The Ramesside State. En J. C. Moreno García (Ed.), Ancient Egyptian Administration (pp. 831-899). Leiden-Boston: Brill.

" Habachi, L. (1984). The Family of Vizier Ibic and His Place Among the Viziers of the Thirteenth Dynasty. Studien zur Altägyptischen Kultur, 11, 113-126.

" Halbwachs, M. ([1925]2004). Los marcos sociales de la memoria. Madrid: Anthropos.

» Hannig, R. (2006). Ägyptisches Wörterbuch II: Mittleres Reich und Zweite Zwischenzeit. Mainz am Rhein: Philipp von Zabern.

» Hari, H. (1965). Horemheb et la reine Moutnedjemet ou la fin d'une dynastie. Genève: Imprimerie La Sirène.

" Harrington, N. (2013). Living with the dead. Ancestor Worship and Mortuary Ritual in Ancient Egypt. Oxford: Oxbow Books.

" Hays, H. M. (2006). The Typological Structure of the Pyramid Texts and its Continuities with Middle Kingdom Mortuary Literature. (Tesis Doctoral inédita), Universidad de Chicago, Estados Unidos de Norteamérica

" Hays, H. M. (2011). The Death of the Democratisation of the Afterlife. En N. Strudwick y H. Strudwick (Eds.), Old Kingdom, New Perspectives: Egyptian Art and Archaeology 2750215o BC (pp. 115-130). Oxford: Oxbow Books.

» Hayes, W. C. (1955). A papyrus of the late Middle Kingdom in the Brooklyn Museum: (Papyrus Brooklyn 35.1446). Nueva York: Brooklyn Museum. 
" Ilin-Tomich, A. (2011). Changes in the Htp-dj-nsw Formula in the Late Middle Kingdom and the Second Intermediate Period. Zeitschrift für Ägyptische Sprache und Altertumskunde, 138, 20-34.

» Ilin-Tomich, A. (2017). From Workshop to Sanctuary. The Production of Late Middle Kingdom Memorial Stelae. Londres: Golden House.

»Jelin, E. (2002). Los trabajos de la memoria. Madrid: Siglo XXI.

» Kemp, B. (1975). Abydos. En W. Helck, y E. Otto (Eds.), Lexikon der Ägyptologie I (pp. 2842). Wiesbaden: Harrassowitz.

» Köhler, U. (1980). Imiut. En W. Helck y E. Otto (Eds.), Lexikon der der Ägyptologie III (pp. 149-150). Wiesbaden: Harrassowitz.

» Lange, H. L. y Schäfer, H. (1908). Catalogue général des antiquités égyptiennes du Musée du Caire, no 20400-20780. Grab-und Denksteine des Mittleren Reichs, II. Berlín: Reichsdruckerei.

» Lapp, G. (1986). Die Opferformel des Alten Reiches: unter Berücksichtigung einiger späterer Formen. Mainz am Rhein: Philipp von Zabern.

» Legrain, G. (1906). Catalogue général des antiquités égyptiennes du Musée du Caire. Nos 42001-42138. Statues et statuettes de rois et de particuliers. Cairo: L'Institut Francais d'Archéologie Orientale.

» Leprohon, R. J. (1996). A Late Middle Kingdom Stela in a Private Collection. En P. Der Manuelian (Ed.), Studies in Honor of William Kelly Simpson (pp. 523-531). Boston: Boston Museum of Fine Art.

" Lichtheim, M. (1988). Ancient Egyptian Autobiographies Chiefly of the Middle Kingdom. A Study and an Anthology. Friburgo: Universitätsverlag Freiburg.

"Logan, T. J. (1990). The Origins of the Jmy-wt Fetish. Journal of the American Research Center in Egypt, 27, 61-69.

" Manning, J. G. (2003). Land and Power in Ptolemaic Egypt: The Structure of Land Tenure. Cambridge: Cambridge University Press.

"Mariette, A. (1880a). Abydos: description des fouilles exécutées sur l'emplacement de cette ville, II. París: L'imprimerie nationale.

"Mariette, A. (188ob). Catalogue général des monuments d'Abydos découverts pendant les fouilles de cette ville. París: L'imprimerie nationale.

»Moeller, N. (2016). The archaeology of urbanism in ancient Egypt: from the predynastic period to the end of the Middle Kingdom. Nueva York: Cambridge University Press.

» Müller, H.W. (1933). Die Totendenkstein des Mittleren Reiches, ihre Genesis, ihre Darstellungen und ihre Komposition. Mitteilungen des Deutschen Instituts für Ägyptische Altertumskunde in Kairo, 4, 165-206.

» Nicholson, P. T. y Shaw, I. (200o). Ancient Egyptian Materials and Technology. Cambridge: Cambridge University Press.

» O'Connor, D. (1969). Abydos and the University Museum: 1898-1969. Expedition, 12(1), 28-39.

» O'Connor, D. (1985). The 'Cenotaphs' of the Middle Kingdom at Abydos. En P. PosenerKriéger (Ed.), Mélanges Gamal Eddin Mokhtar (pp. 161-178). Cairo: Institut Français d'Archéologie Orientale.

" O'Connor, D. (2009). Abydos: Egypt's First Pharaohs and the Cult of Osiris. Londres: Thames and Hudson. 
" O'Neill, B. (2015). Setting the Scene: The deceased and regenerative cult within offering table imagery of the Egyptian Old to Middle Kingdoms (c. 2686 - c.165o BC). Oxford: Archaeopress.

》 Pflüger, K. (1947). The private funerary stelae of the Middle Kingdom and their importance for the study of ancient Egyptian history. Journal of the American Oriental Society, 67(2), 127- 135 .

" Pouls-Wegner, M.A. (2012). New Fieldwork at Abydos: the Toronto Votive Zone Project. Near Eastern Archaeology, 75(3), 178-184.

" Quirke, S. (1988). State and Labour in the Middle Kingdom. A Reconsideration of the term xnrt. Revue d'Egyptologie, 39, 83-106.

»Quirke, S. (1990). The administration of Egypt in the late Middle Kingdom. New Malden: SIA.

》Quirke, S. (2004). Titles and bureaux of Egypt 1850 - 1700 BC. Londres: Golden House Publications.

» Ranke, H. (1935). Die ägyptischen Personennamen (volumen 1). Glückstadt: J. J. Augustin.

" Robins, G. (2016). Meals for the Dead: the image of the deceased seated before a table of offerings. En C. M. Draycott y M. Stamatopoulou (Eds.), Dining and Death: Interdisciplinary Perspectives on the 'Funerary Banquet' in Ancient Art, Burial and Belief (pp. 111-127). Lovaina: Peeters Press.

》 Rosell, P. (2018). Deseos para la eternidad. La fórmula de Abidos y el desarrollo de los misterios de Osiris en las estelas votivas del Reino Medio egipcio. Revista Hélade, 4(2), 43-61.

"Satzinger, H. (1997). Beobachtungen zur Opferformel: Theorie und Praxis. Lingua Aegyptia, 5, 177-188.

"Serpico, M. y White, R. (2000). Resins, amber and bitumen. En P.T. Nicholson e I. Shaw (Eds.), Ancient Egyptian Materials and Technology (pp. 430-474). Cambridge: Cambridge University Press.

"Simpson, W. K. (1974). The Terrace of the Great God at Abydos: The Offering Chapels of Dynasties 12 and 13. New Heaven: Publications of the Pennsylvania-Yale Expedition to Egypt.

"Smither, P. C. (1945). The Semnah despatches. Journal of Egyptian Archaeology, 31, 3-10.

"Snape, S. (1994). Statues and Soldiers at Abydos in the Second Intermediate Period. En C.J. Eyre (Ed.), The Unbroken Reed: Studies in the Culture and Heritage of Ancient Egypt in Honour of A. F. Shore (pp. 304-314). Londres: Egyptian Exploration Society.

"Snape, S. (2011). Ancient Egyptian Tombs: The Culture of Life and Death. Malden: WileyBlackwell.

»Snape, S. (2019). Memorial Monuments at Abydos and the 'Terrace of the Great God'. En I. Regulski (Ed.), Abydos: The Sacred Land at the Western Horizon (255-272). Lovaina: Peeters.

》Spiegel, J. (1973). Die Götter von Abydos. Studien zum ägyptischen Synkretismus. Wiesbaden: Harrassowitz.

» Tefnin, R. (1979). Image et histoire. Réflexions sur l'usage documentaire de l'image égyptienne. Chronique d'Égypte, 54, 218-244.

" van de Walle, E. (2013). sAb Corpus III Prosopographie du début de la XVIIle dynastie à la fin de lépoque ramesside. Bruselas. 
" van den Boorn, G. P. F. (1988). Duties of the Vizier: Civil Administration in the Early New Kingdom. Londres: Kegan Paul International.

》 van Gennep, A. ([1969]2008). Los ritos de paso. Madrid: Alianza.

»Vernus, P. (1986). Le surnom au Moyen Empire: Répertoire, procédés d'expression et structures de la double identité du début de la XIle dynastie a la fin de la XVIle dynastie. Roma: Biblical Institute Press.

"Ward, W.A. (1982). Index of Egyptian administrative and religious titles of the Middle Kingdom: with a glossary of words and phrases used. Beirut: American University of Beirut.

»Westbrook, R. (2003). A History of Ancient Near Eastern Law. Leiden: Brill.

"Whelan, P. (2016). On the Context and Conception of Two 'Trademark' Styles from Late Middle Kingdom Abydos. En G. Miniaci y W. Grajetzki (Eds.), The World of Middle Kingdom Egypt (2000-1550 BC) II, MKS 2 (pp. 285-338). Londres: Golden House.

"Willems, H. O. (1991). Food for the Dead: Remarks on the Structure of the Offering Formula. En W.H. van Soldt (Ed.), Pap uit lemen potten. Papers in memoriam of Mia Pollock (pp. 98-108). Leiden: Publicationes Universitatis Lugdunensis Pollockianae.

"Yamamoto, K. (2015). Abydos and Osiris: The Terrace of the Great God. En A. Oppenheim, D. Arnold, D. Arnold y K. Yamamoto (Eds.), Ancient Egypt transformed: The Middle Kingdom (pp. 250-269). Nueva York: Metropolitan Museum of Art. 